\title{
Green synthesis of zinc oxide nanoparticles using Seaweed aqueous extract and evaluation of antibacterial and ecotoxicological activity
}

\author{
Maryam Kokabi ${ }^{1}$, Moreza Yousefzadi $^{1}{ }^{*}$, Samad Nejad Ebrahimi $^{2}$, Maaroof Zarei $^{3}$ \\ 1- Department of Marine Biology, Faculty of Marine Science and Technology, \\ University of Hormozgan, Bandar Abbas, Iran \\ 2- Department of Phytochemistry, Medicinal Plants and Drugs Research Institute, \\ Shahid Beheshti University, G. C., Evin, Tehran, Iran \\ 3- Department of Chemistry, Faculty of Sciences, University of Hormozgan, Bandar Abbas, Iran
}

(C) 2017 Journal of the Persian Gulf. All rights reserved.

\begin{abstract}
Green synthesized nanomaterials have garnered much attention due to their economic and ecofriendly benefits over common chemical methods of synthesis. In the present study, zinc oxide nanoparticles with an average diameter of $16.51 \mathrm{~nm}$ were successfully biosynthesized using the aqueous extract of the red seaweed Hypnea musciformis. The morphology, purity and quality of biosynthesized Hy-ZnONps were highly comparable with its commercial counterpart with less toxicity. The MIC and MBC values were evaluated and the potential ecotoxicity of $\mathrm{Hy}-\mathrm{ZnO}$ NPs against Artemia salina was investigated in various concentrations $(0,1,5,10,15,25$ $\mu \mathrm{g} / \mathrm{ml}$ ) and mortality rate in 24 hours was evaluated. The findings provide preliminary information for designing cost-effective, eco-friendly green synthesis methods for large-scale production of $\mathrm{ZnONps}$ using marine macroalge.
\end{abstract}

Keywords: Antimicrobial activities, Green synthesis, Hypnea musciformis, Metal oxide, Nanotechnology, Seaweed.

\section{Introduction}

Nanotechnology, in recent years, has received significant expansion in almost every aspect of life including agriculture, food processing/packaging, pharmaceuticals and cosmetics (Ali et al. 2016). The growing concerns on environmental pollution have encouraged the development of biological approach

*Email: Morteza110110@gmail.com for the synthesis of nanoparticles (Elumalai and Velmurugan 2015). In this way, biosynthetic processes of metal oxide nanoparticles are a promising alternative for the synthesis using hazardous chemical solvents. The processes involve using biological materials such as herbal extracts, bacteria, and enzymes as reducing and stabilizing factors for the green synthesis of nanoparticles (Ahmad et al. 2012; Sharma et al. 2018; Siddiqi et al. 2018). 
Zinc oxide $(\mathrm{ZnO})$ belongs to the class of metal oxides that is commercially very important due to the remarkable applications in various industrial fields such as catalysis, solar cells, paints, UV lightemitting devices, electronic devices, biomedicine and cosmetic (Osman et al. 2017; Sangeetha et al. 2011; Sharma et al. 2018).

Seaweeds or marine macroalgae with their diverse bioactive compounds have shown immense potential for using in different aspects of biotechnology. Marine macroalgae cultivated in aquaculture can be a sustainable source of biomass for using in green synthesis of metal oxide nanoparticles. Hypnea musciformis is a red macroalgae belonging to the Cystocloniaceae family. It is fast-growing opportunistic seaweed that dominated the macroalgal communities in some eastern coasts of Qeshm Island from April to May (Kokabi et al. 2016). This species is a carrageenan yielding seaweed commercially cultivated throughout the world (Vadlapudi and Amanchy 2017). There are 10 species of Hypnea reported from south-east of Iran (Kokabi and Yousefzadi 2015) that some of them could easily culture in the coastal area with no requirement of land and freshwater.

Currently, a number of terrestrial plants have been successfully used for the synthesis of $\mathrm{ZnO}$ nanoparticles (Elumalai and Velmurugan 2015; Jafarirad et al. 2016; Vijayakumar et al. 2018), but only limited reports are available for green synthesis of this nanoparticle using seaweeds (Azizi et al. 2014; Pandimurugan and Thambidurai 2016) and Rhodophyta, in particular. Although, the synthesis of silver nanoparticles using H. musciformis has been reported before (Vadlapudi and Amanchy 2017), in this study, $H$. musciformis was considered due to its novelty and biomass production capacity for the biosynthesis of zinc oxide nanoparticles. Biosynthesis of $\mathrm{ZnO}$ nanoparticles using marine macroalgae has advantages over terrestrial plants since they do not compete with agricultural land or freshwater resources. Therefore, they are a sustainable source for large-scale production of green synthesis of nanoparticles.

This study describes the green synthesis, characterization and eco-toxicological activity of ZnONPs obtained by biological techniques using $H$. musciformis for the first time. Furthermore, MIC (Minimum inhibitory concentration) and MBC (minimum bactericidal concentration) method against bacterial strains were applied to evaluate the antibacterial activity of biosynthesized NPs.

\section{Materials and Methods}

\subsection{Preparation of the H. musciformis extracts}

The red algae $H$. musciformis was collected in early May from Qeshm Island, Hormozgan, Iran. The collected biomass was washed thoroughly with tap water to clean up and shade-dried. The algal powder $(1.0 \mathrm{~g})$ was obtained by the grinder and extracted with distilled water at $85^{\circ} \mathrm{C}$ for 15 minutes. After cooling down of solution, until room temperature, the sample was centrifuged (1000 rpm) to remove debris. The obtained extract was stored at $4^{\circ} \mathrm{C}$ and used in the biosynthesis of $\mathrm{ZnO}$.

\subsection{Synthesis of Hy- ZnONPs}

An aqueous extract of $\mathrm{H}$. musciformis was mixed with the solution of $0.2 \mathrm{M}$ zinc nitrate $(1: 10 \mathrm{v} / \mathrm{v})$ under vigorous stirring at $60^{\circ} \mathrm{C}$ for 2 hours in an aqueous bath system to complete the reaction. After adjusting the $\mathrm{pH}$ of the solution on six, the appearance of a white precipitate in the reaction vessels suggested the formation of $\mathrm{ZnO}$ nanoparticles. Then, the solution was centrifuged at $6000 \mathrm{rpm}$ for 10 minutes and the resulting precipitate washed thoroughly with deionized water. The product was dehydrated in the oven at $80^{\circ} \mathrm{C}$ overnight and calcinated at $450^{\circ} \mathrm{C}$ for 2 hours to 
completely converted $\mathrm{Zn}(\mathrm{OH}) 2$ into $\mathrm{ZnO}$ nanoparticles. The prepared biosynthesized $\mathrm{ZnO}$ nanoparticles were used for further characterization for their optical and nanostructural properties.

\subsection{Characterization of zinc oxide NPs}

For evaluating the synthesis of nanoparticles, the optical absorption spectra of biosynthesized nanoparticles were recorded using a UV-vis spectrophotometer (Shimadzu, UV-2501PC) in the wavelength range 200-700 nm. Fourier transform infrared (FT-IR) spectra were obtained for the analysis of functional groups using an FT-IR spectrometer (Tensor 27, Bruker). $\mathrm{ZnO}$ nanoparticle powder of $H$. musciformis was homogenized with $\mathrm{KBr}$ in a ratio of 1:100 and pellets were prepared for the FT-IR measurements. The IR spectra of alga extracts, ZnONPs obtained from that, and commercial ZnONPs (US-NANO) were analyzed as comparisons. The purity and grain size of the dried powder of ZnONPs was evaluated by X-ray diffraction (XRD) method using $\mathrm{Cu} \mathrm{K} \alpha$ radiation in wavelength $\lambda=0.15406 \mathrm{~nm}$ over the scan range of $2 \theta=1-80^{\circ}$. Morphology of the Hy-ZnONPs along with the elemental analysis (EDXA) was determined via field emission scanning electron microscopy (FESEM with EDXA, MIRA3 TESCAN) using Au element for coating samples.

The mean crystalline size of biosynthesized ZnONPs was estimated using the Debye Scherrer's formula as follows:

$$
D=\frac{k \lambda}{\beta \cos \theta}
$$

In which $\mathrm{D}$ is the mean crystallite size, $\mathrm{K}$ is the Scherrer constant (0.93), $\lambda$ is the $\mathrm{X}$-ray wavelength was used (1.5406 $\AA$ ), $\beta$ is the full width at half the maximum (FWHM) of the considered peak, and $\theta$ is the Bragg angle (Patterson 1939).

\subsection{Antibacterial evaluation}

Two standard strains of Gram-positive (Staphylococcus aureus) and Gram-negative (Escherichia coli) bacteria were used to assess the antibacterial potential of nanoparticles by serial dilution method. Suspensions of both Hy-ZnONPs and commercial $\mathrm{ZnO}$ nanoparticles along with alga extract were prepared in Muller Hinton broth medium in various concentrations (from 0.125 to 32 $\mathrm{mg} / \mathrm{ml}$ ) under the sterilized conditions. After incubation for $24 \mathrm{~h}$ in $37{ }^{\circ} \mathrm{C}$, the lowest concentration of samples that prevented the growth of the bacteria was recorded as MIC.

Those concentrations with inhibition performance in MIC test were sub-cultured into the sterile nutrient agar media for MBC screening. All treatments were exposed for $24 \mathrm{~h}$ at $37^{\circ} \mathrm{C}$. The lowest concentration of nanoparticles or algal extract with no bacterial growth on the surface of culture media was considered as MBC value (Rajabi et al. 2017).

\subsection{Ecotoxicity assay}

Artemia cytotoxicity assay was carried out using the newly hatched free-swimming nauplii of Artemia salina. The recently hatched larva were isolated from nonhatched cysts based on their positive phototropism and 10 larvae transferred to each well of a 24 -well polystyrene plate that contained $1 \mathrm{~mL}$ of artificial seawater (Gambardella et al. 2014) with suspensions of chosen concentrations $(0,1,5,10,15$, $25 \mu \mathrm{g} / \mathrm{ml}$ ) of commercial ZnONPs, Hy-ZnONPs and DMSO as positive control. Artificial seawater with no chemical was taken as blank or negative control. All of the experiments were performed in triplicate. After $24 \mathrm{~h}$ of exposure, the percent mortality of Artemia treatments was calculated using the following formula:

$$
\text { Mortality }(\%)=[(\mathrm{m}-\mathrm{M}) / \mathrm{S}] \times 100
$$


In which $\mathrm{m}$ is the mean number of dead nauplii in treatments, $\mathrm{M}$ is the mean number of dead nauplii in positive control and $\mathrm{S}$ is the mean number of live nauplii in positive control.

\section{Results}

\subsection{Spectrophotometry}

The UV-Vis absorption spectrum of obtained biosynthesized nanoparticles showed a sharp absorbance peak at $370 \mathrm{~nm}$ (Figure 1). The spectra of Hy-ZnONPs, and the commercial ZnONPs, revealed the same absorption peak at $370 \mathrm{~nm}$ while the algal extract and $\mathrm{Zn}\left(\mathrm{NO}_{3}\right)_{2}$ solution was different (Figure $1)$.

\subsection{X-ray diffraction}

The phase and crystalline structure of biosynthesized nanoparticles were investigated by X- ray diffraction measurements as shown in Figure 3. The diffraction pattern showed sharp peaks at 2Theta values of $31.7,34.3,36.2,47.4,56.5,62.8,67.8$, and 69.1 proves the good crystalline nature of nanoparticles and corresponds to (100), (002), (101), (102), (110), (103), (112) and (201) reflection patterns respectively for $\mathrm{ZnO}$ (Figure 2).

All of the diffraction peaks confirmed the spherical and hexagonal structure of biosynthesized Hy-ZnONPs via comparison with JCPDS card No. 89-7102 (Hong et al. 2009; Rajiv et al. 2013). Furthermore, the strong and narrow diffraction peaks confirm the crystalline nature as well as the high purity of biosynthesized Hy-ZnONPs and the absence of any other impurities (Figure 2). The average particle size of the biosynthesized and the commercial $\mathrm{ZnO}$ nanoparticles was found to be 16.51 and $16.83 \mathrm{~nm}$, respectively from their XRD line broadening measurement using Debye-Scherrer formula.

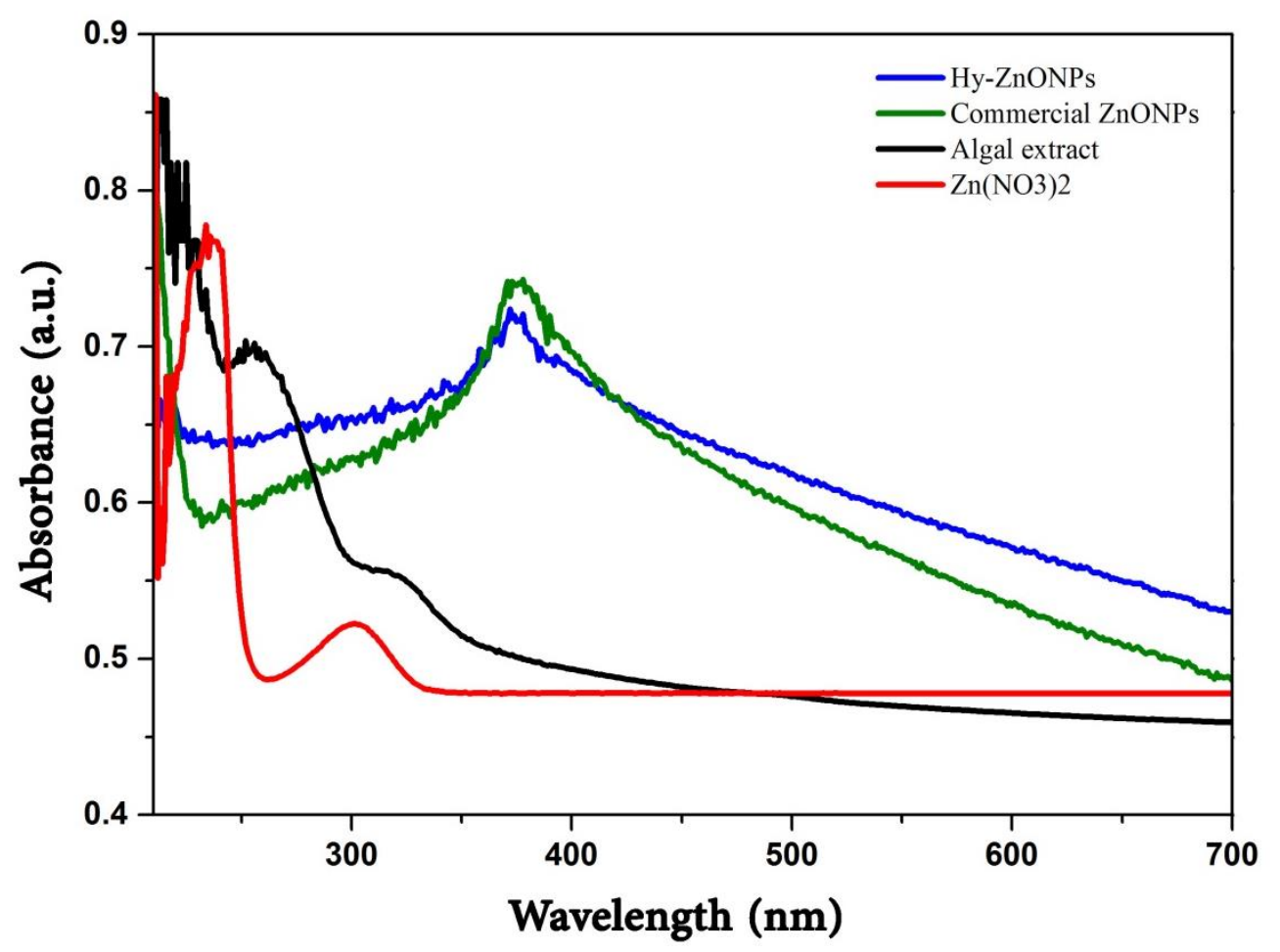

Fig 1: Comparison of UV-Vis spectrum of Hypnea musciformis extract, zinc nitrate solution, $\mathrm{Hy}-\mathrm{ZnO}$ nanoparticles, and the commercial $\mathrm{ZnO}$ nanoparticles. 


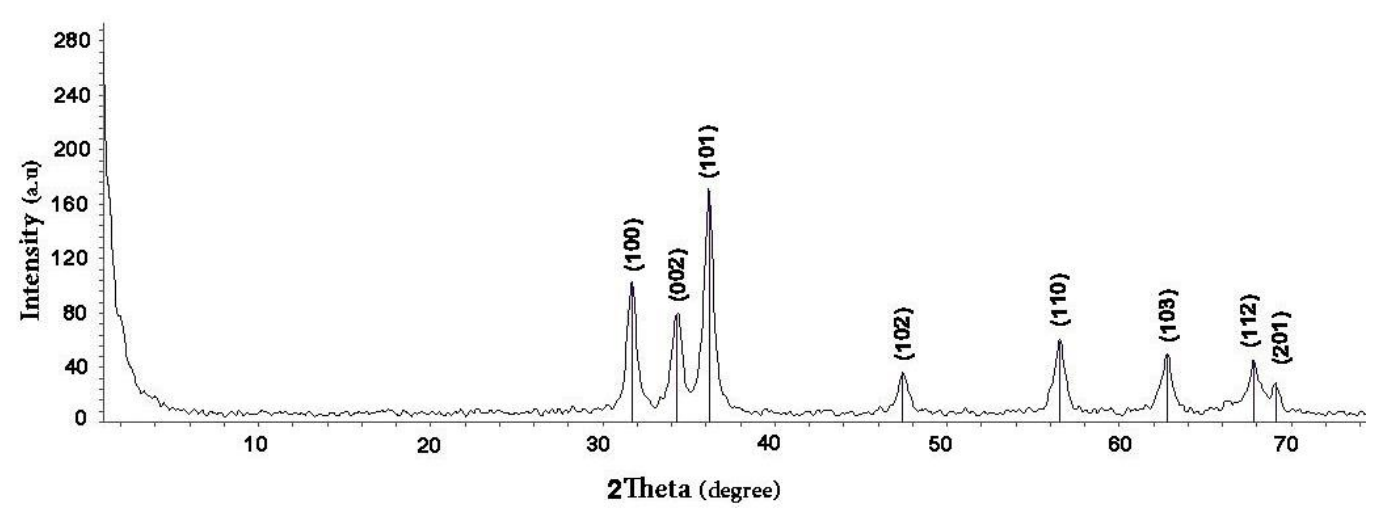

Fig 2: XRD pattern of biosynthesized ZnO NPs using Hypnea musciformis extract.

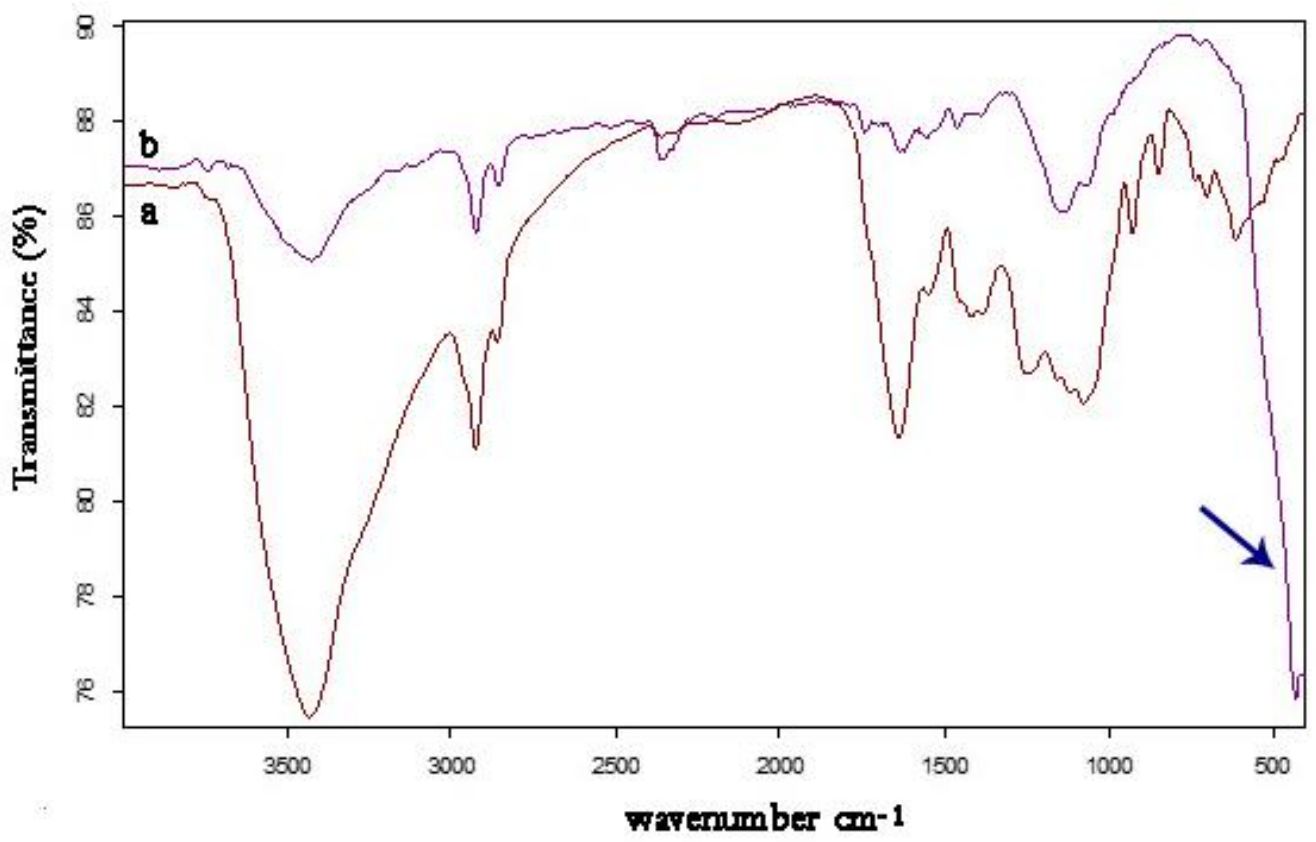

Fig 3: FT-IR spectra of (a) aqueous extracts of H. musciformis, and (b) ZnONPs synthesized using alga extract.

\subsection{FTIR analysis}

The possible functional groups involved in different zinc oxide nanoparticles were identified using FT-IR analysis. The FT-IR spectra of alga extract and biosynthesized zinc oxide nanoparticles in the range of $400-4000 \mathrm{~cm}^{-1}$ are shown in Figure 3. The signal at $3421 \mathrm{~cm}^{-1}$ corresponds to the $\mathrm{O}-\mathrm{H}$ group. The absorption band at $2924 \mathrm{~cm}^{-1}$ represented $\mathrm{C}-\mathrm{H}$ stretch of aliphatic compounds (Pandimurugan and Thambidurai 2016). The $\mathrm{C}=\mathrm{N}$ group in alga extract showed a sharp band at $1634 \mathrm{~cm}^{-1}$. Moderate levels of absorption in the region covering $1000-$ $1300 \mathrm{~cm}^{-1}$ implied the presence of C-O group (Figure $3 b)$. The spectrum of Hy-ZnONPs showed a new sharp peak at $430 \mathrm{~cm}^{-1}$ which is corresponding to zinc-oxygen stretching mode (Pandimurugan and Thambidurai 2016). Generally, the peak in the range of 400 to $600 \mathrm{~cm}^{-1}$ is attributed to $\mathrm{Zn}-\mathrm{O}$ stretching vibrations (Sharma and Ghose 2015) (Figure 3a). 


\subsection{FESEM and EDAX analysis}

Field emission scanning electron microscopy (FESEM) was used to visualize the topology and size of biosynthesized nanoparticles. Figure 4 represents spherical morphology and agglomeration of commercial $\mathrm{ZnO}$ nanoparticles with average size of 29-35 $\mathrm{nm}$ in compare to biosynthesized Hy-ZnONps with uniform distribution and smaller size of 26-35
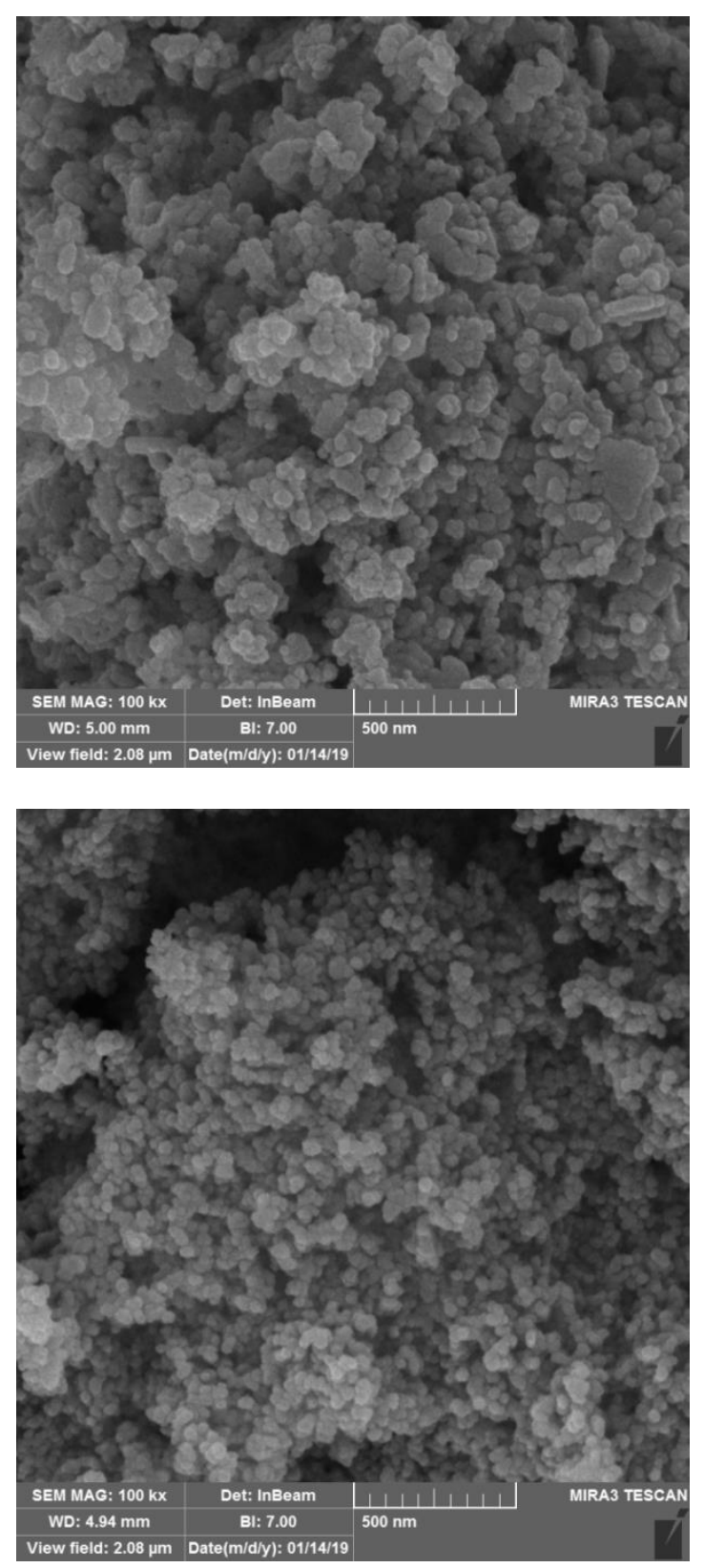

$\mathrm{nm}$, possibly to reflect less agglomeration in biosynthesized ZnONps. The agglomeration occurred probably during the process of precipitation and drying. Energy dispersive $\mathrm{X}$-ray analysis (EDXA) of the synthesized nanoparticle confirms the presence of only zinc and oxygen elements in the Hy-ZnONPs powder with no impurities (Figure 5) which was in good agreement with the X-ray diffraction measurements.
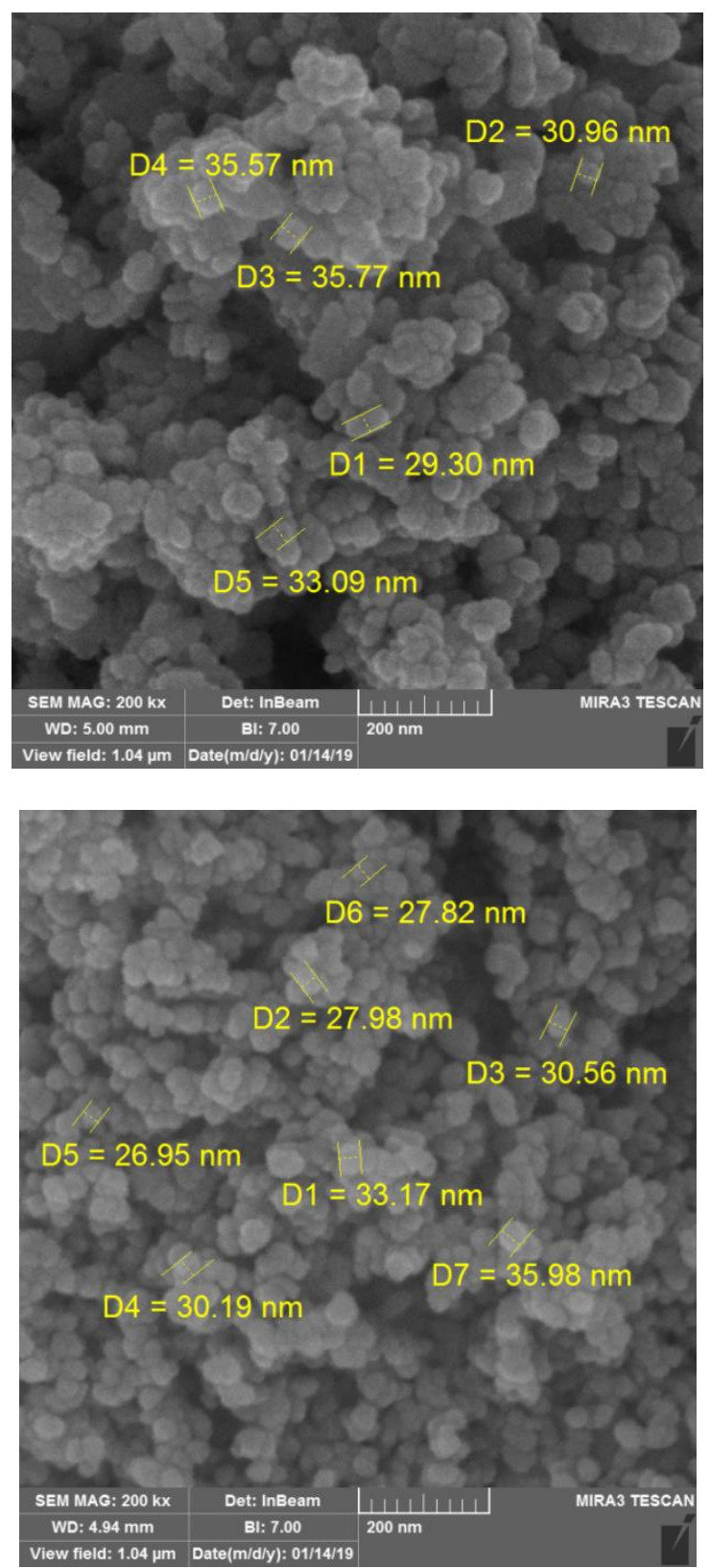

Fig 4: FESEM image of comercial ZnO NPs (above) vs H. musciformis formed ZnO NPs (below) in two different magnification 


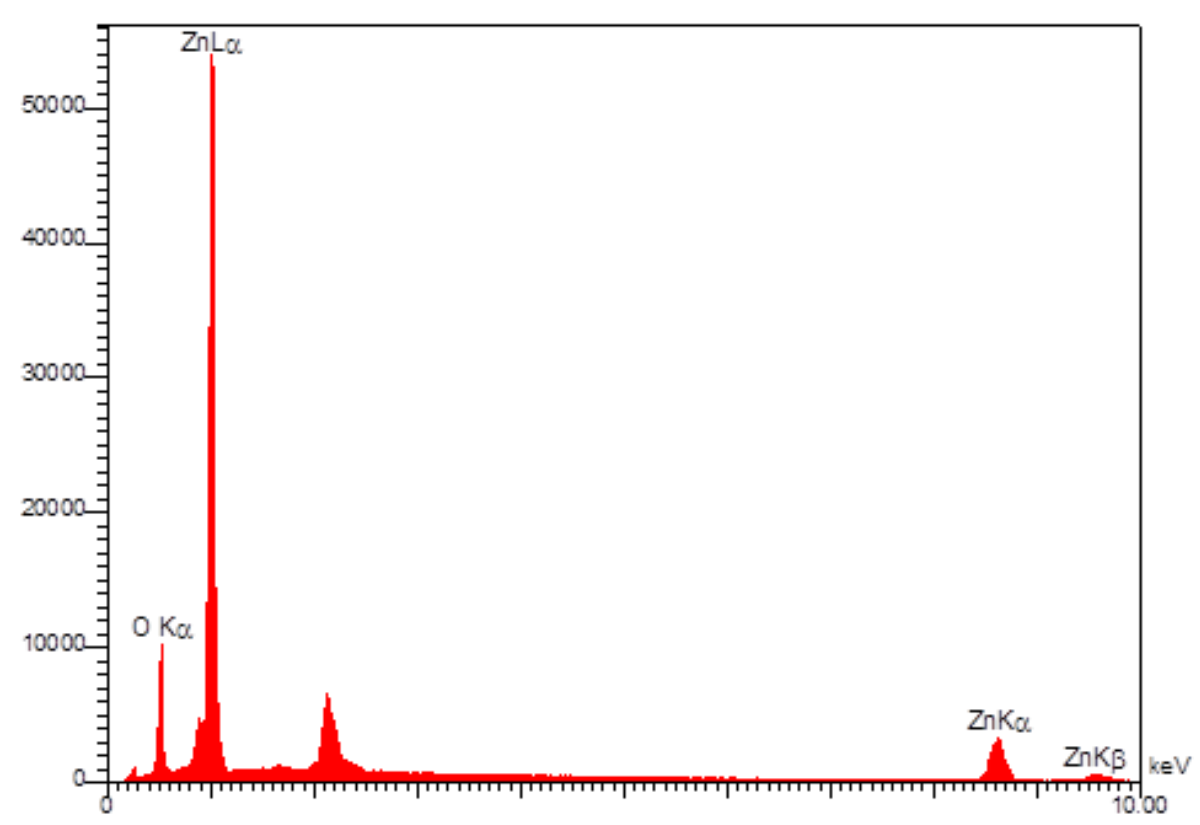

Fig 5: EDX analysis plot of ZnONPs synthesized using Hypnea musciformis extract

\subsection{Antibacterial evaluation of $\mathrm{ZnONPs}$}

The MIC and MBC values of the aqueous algal extract, Hy-ZnONPs and commercial ZnONPs against $S$. aureus and E. coli bacterial strains are presented in Table 1. No antibacterial activity was observed for aqueous extract of $H$. musciformis, while both zinc oxide NPs displayed good results. The growth of both bacterial strains was completely inhibited at $0.12 \mathrm{mg} / \mathrm{ml}$ concentration of commercial ZnONPs whereas Hy-ZnONPs prevented the growth of $S$. aureus and E. coli at a concentration of 0.25 and $0.5 \mathrm{mg} / \mathrm{ml}$, respectively. The results indicated that $S$. aureus is more susceptible to ZnONPs. It was also noted that the bactericidal potential of both nanoparticles were lower than that of Ampicillin. However, the MIC test of commercial ZnONPs showed the same $(0.12 \mathrm{mg} / \mathrm{ml})$ and better value $(0.12$ $\mathrm{mg} / \mathrm{ml}$ ) for $S$. aureus and $E$. coli, respectively compared with the reference. Interestingly, HyZnONPs exhibited higher bactericidal activities than its commercial counterpart (Table 1).

3.6. The ecotoxicity of $\mathrm{ZnO} \mathrm{NPs}$ against Artemia salina

The results of this study revealed that low concentrations of ZnONPs did not induce significant mortalities on Artemia after $24 \mathrm{~h}$. The commercial ZnONPs displays a higher toxicity than its biosynthesized equivalent (Table 2). In comparison, DMSO was 5-10 times more toxic to Artemia than both kinds of zinc oxide nanoparticles.

Table 1: Assessment of MIC and MBC of ZnONPs (mg/ml) against bacterial strains

\begin{tabular}{|c|c|c|c|c|c|c|c|c|}
\hline \multirow[t]{2}{*}{ Bacteria } & \multicolumn{2}{|c|}{ Ampicillin } & \multicolumn{2}{|c|}{$\begin{array}{c}\text { H. musciformis } \\
\text { extract }\end{array}$} & \multicolumn{2}{|c|}{$\begin{array}{c}\text { Commercial } \\
\text { ZnONPs }\end{array}$} & \multicolumn{2}{|c|}{ Hy-ZnONPs } \\
\hline & MIC & MBC & MIC & MBC & MIC & MBC & MIC & $\mathrm{MBC}$ \\
\hline S. aureus & 0.12 & 0.21 & $<32$ & 0 & 0.12 & 8 & 0.25 & 4 \\
\hline E. coli & 0.24 & 0.41 & $<32$ & 0 & 0.12 & $<8$ & 0.5 & 8 \\
\hline
\end{tabular}


Table 2. Percent mortality values of Artemia nauplii measured for $24 \mathrm{~h}$ exposure to different concentrations of DMSO and aqueous suspensions of ZnONPs.

\begin{tabular}{|c|c|c|}
\hline Chemicals & $\begin{array}{c}\text { Concentration } \\
(\mu \mathrm{g} / \mathrm{ml})\end{array}$ & $\begin{array}{c}\text { Mortality } \\
(\%)\end{array}$ \\
\hline \multirow{6}{*}{ commercial ZnONPs } & Control & 0 \\
\hline & 1 & 0 \\
\hline & 5 & $5 \pm 0.5$ \\
\hline & 10 & $7 \pm 0.5$ \\
\hline & 15 & $8 \pm 0.7$ \\
\hline & 25 & $11 \pm 1.7$ \\
\hline \multirow{6}{*}{ Hy-ZnONPs } & Control & 0 \\
\hline & 1 & 0 \\
\hline & 5 & 0 \\
\hline & 10 & $4 \pm 0.4$ \\
\hline & 15 & $5 \pm 0.1$ \\
\hline & 25 & $7 \pm 0.8$ \\
\hline \multirow{6}{*}{ DMSO } & Control & 0 \\
\hline & 1 & 0 \\
\hline & 5 & $5 \pm 0.8$ \\
\hline & 10 & $11 \pm 0.7$ \\
\hline & 15 & $22 \pm 1.2$ \\
\hline & 25 & $72 \pm 2.5$ \\
\hline
\end{tabular}

Water temperature and salinity were maintained at $24 \pm 2{ }^{\circ} \mathrm{C}, 29-30 \%$, respectively. Each exposure is made in triplicate in artificial seawater.

\section{Discussion}

Recently, various types of algae have been applied in green nanotechnology as reducing agent to form nanometals (Sharma et al. 2015). In current study, zinc oxide nanoparticles with an average diameter of $16.51 \mathrm{~nm}$ were successfully biosynthesized using the aqueous extract of the red seaweed $H$. musciformis.

The UV- visible absorption study is one of the most prominent and easy way to find if the $\mathrm{ZnO}$ nanoparticles synthesize. Talam et al. 2012, reported two absorption bands at about 355 and $258 \mathrm{~nm}$ on the absorbance spectra of $\mathrm{ZnO}$ nanoparticles. Our study supported their findings. Elumalai and
Velmurugan (2015), reported the same absorption peak as findings of this study for the green synthesized ZnONPs using aqueos extract of Indian lilac tree (Azadirachta indica L.). Ali et al. (2016) also recorded the absorption peak of $375 \mathrm{~nm}$ for their biosynthesized zinc oxide nanoparticles by the use of Aloe vera extract.

Marine algae extracts contain a variety of functional groups such as amino, sulfate, carboxyl and hydroxyl groups which can take part in the conversion of $\mathrm{Zn}\left(\mathrm{NO}_{3}\right)_{2}$ to zinc oxide nanoparticles and subsequent stabilization of them (Azizi et al. 2014; Vijayakumar et al. 2018). In this study, the FT-IR spectrums indicate that the $\mathrm{O}-\mathrm{H}$ and $\mathrm{C}=\mathrm{N}$ stretchings played major roles during the formation 
of Hy-ZnONPs since they are highly shifted. These bands indicate that polysaccharides and imine compounds are abundant in aqueous extract of $H$. musciformis. Since this alga species is carrageenan rich seaweed, it can be postulated that the polysaccharide participated in the reaction is carrageenan. This water soluble macromolecule could have acted as stabilizing agent preventing the aggregation of nanoparticles in reaction solution.

The obtained Hy-ZnONps are smaller than $\mathrm{ZnO}$ nanoparticles reported by Azizi et al. (2014). In their study, FESEM analysis of biosynthesized ZnONPs showed the average size ranged between 30 and 57 $\mathrm{nm}$ using the brown marine macroalgae Sargassum muticum. It is also smaller than the biosynthesized $\mathrm{ZnO}$ nanoparticles $(40 \mathrm{~nm})$ from the leaf extract of Azadirachta indica (L.) reported by Elumalai and Velmurugan (2015). Ishwarya et al. 2018 reported the average size of $10-50 \mathrm{~nm}$ for $U$. lactuca fabricated $\mathrm{ZnO}$ NPs with sponge-like asymmetrical shape, while Hy-ZnONps in this study showed uniform spherical morphology. The morphological properties of shape, size, and crystalline form of nanoparticles depend on various factors such as preparation methods, precursors and organic ligands (usually in the form of surfactants). In reaction solution, ligands (surfactant) affect the growth of the nanoparticles strongly. Generally, stronger chelates with metals will result in smaller particles (Ling et al. 2014). H. musciformis is carrageenan yielding seaweed rich in sulphates, carboxyl and hydroxyl groups that gave it an amphiphilic properties (Vadlapudi and Amanchy 2017). These functional groups interact with the zinc surface and form chelation with $\mathrm{Zn}^{2+}$ via chemical adsorption. Ultimately, heating and calcination of obtained powder led to the cleavage of $\mathrm{Zn}$-seaweed chelate to form nanozinc oxide (Pandimurugan and Thambidurai 2016). Our results are comparable to commercial $\mathrm{ZnONps}$ in size with less agglomeration probably due to bioactive compounds in the algal extract act as stabilizers that keeps the particles separated, avoiding aggregation and coalescence.

The results of antibacterial activity were in accordance with previous researches that reported zinc oxide as bacteriostatic at the low concentration and bactericidal at high concentrations (Ali et al. 2016). Two possible mechanisms were suggested to explain the inhibition of bacteria, namely, ROS generation on the surface of this metal oxide and interaction of zinc with cell membrane of bacteria through adhesion of $\mathrm{ZnO}$ particle (Ann et al. 2014; Mirzaei and Darroudi 2017).

Artemia assay is a cheap, available, simple and reliable method for ecotoxicity studies. Artemia or brine shrimp is a nonselective filter feeder that can normally ingest particles with size of up to $50 \mu \mathrm{m}$. Adaptability of Artemia specimens to laboratory conditions makes this genus a valuable model organism for a great variety of toxicity studies (Nunes et al. 2006). In current study, less than $10 \%$ mortality was observed in the Artemia nauplii exposed to all of the concentrations of the HyZnONps, including the highest. The results revealed less toxicity of biosynthesized ZnONPs in comparison with commercial $\mathrm{ZnONPs}$ as well as DMSO. Soniya et al. 2015 also revealed that the low concentrations of ZnONPs have no toxic effect on Artemia salina. Identifying hazardous impacts of nanoparticles on natural organisms is difficult because of their diverse properties and the complexity of biological systems (Contini et al. 2017). Earlier studies revealed that different phylogenic groups may exhibit various responses and sensitivities towards zinc oxide nanoparticles. For example, Wong et al. 2010 assessed the toxicity of ZnONPs on five selected marine organisms. They concluded that ZnONPs was more toxic towards diatoms, but relatively less toxic towards crustaceans and fish. The toxicity of zinc oxide nanoparticles 
could be mainly attributed to dissolve $\mathrm{Zn}^{2+}$ ions (Aruoja et al. 2009). As it known, this metal ion is needed as microelements for normal functioning of live cells (Mortimer et al. 2010).

The results of characterization as well as bioassay confirmed that the newly synthesized ZnONPs is potentially an eco-friendly alternative for commercial/ chemical ZnONPs and the $H$. musciformis can provide a cost-effective natural source of raw materials for preparation of this nanoparticle.

\section{Acknowledgments}

The authors would like to thank the University of Hormozgan (grant No. 96/200/163).

\section{References}

Ahmad, N., Sharma, S. and Rai, R., 2012. Rapid green synthesis of silver and gold nanoparticles using peels of Punica granatum. Advanced Materials Letters, 3(5): 376-380.

https://doi.org/10.5185/amlett.2012.5357

Ali, K., Dwivedi, S., Azam, A., Saquib, Q., Al-Said, M.S., Alkhedhairy, A.A. and Musarrat, J., 2016. Aloe vera extract functionalized zinc oxide nanoparticles as nanoantibiotics against multi-drug resistant clinical bacterial isolates. Journal of Colloid Interface Science, 472: 145-156.

https://doi.org/10.1016/j.jcis.2016.03.021

Ann, L.C., Mahmud, S., Bakhori, S.K.M., Sirelkhatim, A., Mohamad, D., Hasan, H., Seeni, A. and Rahman, R.A., 2014. Antibacterial responses of zinc oxide structures against Staphylococcus aureus, Pseudomonas aeruginosa and Streptococcus pyogenes. Ceramics International, 40(2): 2993-3001. https://doi.org/10.1016/j.ceramint.2013.10.008
Aruoja, V., Dubourguier, H.C., Kasemets, K. and Kahru, A., 2009. Toxicity of nanoparticles of $\mathrm{CuO}, \mathrm{ZnO}$ and $\mathrm{TiO} 2$ to microalgae Pseudokirchneriella subcapitata. Science of the Total Environment, 407(4): 1461-1468. https://doi.org/10.1016/j.scitotenv.2008.10.053

Azizi, S., Ahmad, M.B., Namvar, F. and Mohamad, R., 2014. Green biosynthesis and characterization of zinc oxide nanoparticles using brown marine macroalga Sargassum muticum aqueous extract. Materials Letters, 116: 275-277. https://doi.org/10.1016/j.matlet.2013.11.038

Contini, C., Schneemilch, M., Gaisford, S. and Quirke, N., 2017. Nanoparticle-membrane interactions. Journal of Experimental Nanoscience, 13(1): 62-81.

https://doi.org/10.1080/17458080.2017.1413253

Elumalai, K. and Velmurugan, S., 2015. Green synthesis, characterization and antimicrobial activities of zinc oxide nanoparticles from the leaf extract of Azadirachta indica (L.). Applied Surface Science, 345: 329-336.

https://doi.org/10.1016/j.apsusc.2015.03.176

Gambardella, C., Mesaric, T., Milivojevic, T., Sepcic, K., Gallus, L., Carbone, S., Ferrando, S. and Faimali, M., 2014. Effects of selected metal oxide nanoparticles on Artemia salina larvae: evaluation of mortality and behavioural and biochemical responses. Environmental Monitoring Assess, 186(7): 4249-4259.

https://doi.org/10.1007/s10661-014-3695-8

Hong, R.Y., Li, J.H., Chen, L.L., Liu, D.Q., Li, H.Z., Zheng, Y. and Ding, J., 2009. Synthesis, surface modification and photocatalytic property of $\mathrm{ZnO}$ nanoparticles. Powder Technology, 189(3): 426432.

https://doi.org/10.1016/j.powtec.2008.07.004 
Ishwarya, R., Vaseeharan, B., Kalyani, S., Banumathi, B., Govindarajan, M., Alharbi, N.S., Kadaikunnan, S., Al-Anbr, M.N., Khaled, J.M. and Benelli, G., 2018. Facile green synthesis of zinc oxide nanoparticles using Ulva lactuca seaweed extract and evaluation of their photocatalytic, antibiofilm and insecticidal activity. Journal of Photochemistry and Photobiology B: Biology, 178: 249-258.

https://doi.org/10.1016/j.jphotobiol.2017.11.006

Jafarirad, S., Mehrabi, M., Divband, B. and KosariNasab, M., 2016. Biofabrication of zinc oxide nanoparticles using fruit extract of Rosa canina and their toxic potential against bacteria: A mechanistic approach. Materials Science and Engineering C, 59: 296-302.

https://doi.org/10.1016/j.msec.2015.09.089

Journal of the Persian Gulf (Marine Science)/Vol. 8/No. 27/ March 2017/12/51-62.

Kokabi, M. and Yousefzadi, M., 2015. Checklist of the marine macroalgae of Iran. Botanica Marina, 58(4): 307-320.

https://doi.org/10.1515/bot-2015-0001

Kokabi, M., Yousefzadi, M., Razaghi, M. and Feghhi, M.A., 2016. Zonation patterns, composition and diversity of macroalgal communities in the eastern coasts of Qeshm Island, Persian Gulf, Iran. Marine Biodiversity Records, 9(1): 1-11. https://doi.org/10.1186/s41200-016-0096-4

Ling, D., Hackett, M.J. and Hyeon, T., 2014. Surface ligands in synthesis, modification, assembly and biomedical applications of nanoparticles. Nano Today, 9(4): 457-477. https://doi.org/10.1016/j.nantod.2014.06.005

Mirzaei, H. and Darroudi, M., 2017. Zinc oxide nanoparticles: Biological synthesis and biomedical applications. Ceramics International, 43(1): 907914.

https://doi.org/10.1016/j.ceramint.2016.10.051
Mortimer, M., Kasemets, K. and Kahru, A., 2010. Toxicity of $\mathrm{ZnO}$ and $\mathrm{CuO}$ nanoparticles to ciliated protozoa Tetrahymena thermophila. Toxicology, 269(2-3): 182-189.

https://doi.org/10.1016/j.tox.2009.07.007

Nunes, B.S., Carvalho, F.D., Guilhermino, L.M. and Van Stappen, G., 2006. Use of the genus Artemia in ecotoxicity testing. Environmental Pollution, 144(2): 453-462.

https://doi.org/10.1016/j.envpol.2005.12.037

Osman, E.b., Moriga, T., Murai, K.-i. and Rashid, M.W.b.A., 2017. Study of morphology and electrical properties of indium zinc oxide-modified kenaf fiber. Industrial Crops and Products, 100: 171-175.

https://doi.org/10.1016/j.indcrop.2017.02.029

Pandimurugan, R. and Thambidurai, S., 2016. Novel seaweed capped $\mathrm{ZnO}$ nanoparticles for effective dye photodegradation and antibacterial activity. Advanced Powder Technology, 27(4): 1062-1072. https://doi.org/10.1016/j.apt.2016.03.014

Patterson, A., 1939. The Scherrer formula for X-ray particle size determination. Physical Review, 56: 978-982.

https://doi.org/10.1103/PhysRev.56.978

Rajabi, H.R., Naghiha, R., Kheirizadeh, M., Sadatfaraji, H., Mirzaei, A. and Alvand, Z.M., 2017. Microwave assisted extraction as an efficient approach for biosynthesis of zinc oxide nanoparticles: Synthesis, characterization, and biological properties. Materials Science and Engineering C, 78: 1109-1118.

https://doi.org/10.1016/j.msec.2017.03.090

Rajiv, P., Rajeshwari, S. and Venckatesh, R., 2013. Bio-fabrication of zinc oxide nanoparticles using leaf extract of Parthenium hysterophorus L. and its size-dependent antifungal activity against plant fungal pathogens. Spectrochimica Acta Part A: Molecular and Biomolecular Spectroscopy, 112: 
384-387.

\section{https://doi.org/10.1016/j.saa.2013.04.072}

Sangeetha, G., Rajeshwari, S. and Venckatesh, R., 2011. Green synthesis of zinc oxide nanoparticles by aloe barbadensis miller leaf extract: Structure and optical properties. Materials Research Bulletin, 46(12): 2560-2566.

https://doi.org/10.1016/j.materresbull.2011.07.046

Sharma, D., Sabela, M.I., Kanchi, S., Bisetty, K., Skelton, A.A. and Honarparvar, B., 2018. Green synthesis, characterization and electrochemical sensing of silymarin by $\mathrm{ZnO}$ nanoparticles: Experimental and DFT studies. Journal of Electroanalytical Chemistry, 808: 160-172. https://doi.org/10.1016/j.jelechem.2017.11.039

Sharma, R.K. and Ghose, R., 2015. Synthesis of zinc oxide nanoparticles by homogeneous precipitation method and its application in antifungal activity against Candida albicans. Ceramics International, 41(1): 967-975.

https://doi.org/10.1016/j.ceramint.2014.09.016

Siddiqi, K.S., Ur Rahman, A., Tajuddin and Husen, A., 2018. Properties of zinc oxide nanoparticles and their activity against microbes. Nanoscale Research Letter, 13(1): 141. https://doi.org/10.1186/s11671-018-2532-3

Soniya, P., Kumaresn, K., Parthiban, D., Arun, N. and Kumaravel, P., 2015. Effect of zinc oxide nanoparticles on Artemia salina. Research Journal of Pharmaceutical Dosage Forms and Technology, 7(2): 103-110. https://doi.org/10.5958/0975-4377.2015.00015.4

Talam, S., Karumuri, S.R. and Gunnam, N., 2012. Synthesis, characterization, and spectroscopic properties of zno nanoparticles. ISRN Nanotechnology, 2012: 1-6. https://doi.org/10.5402/2012/372505

Vadlapudi, V. and Amanchy, R., 2017. Synthesis, characterization and antibacterial activity of silver nanoparticles from red algae, Hypnea musciformis. Advances in Biological Research, 11(5): 242-249.

Vijayakumar, S., Mahadevan, S., Arulmozhi, P., Sriram, S. and Praseetha, P.K., 2018. Green synthesis of zinc oxide nanoparticles using Atalantia monophylla leaf extracts: Characterization and antimicrobial analysis. Materials Science in Semiconductor Processing, 82: 39-45.

https://doi.org/10.1016/j.mssp.2018.03.017

Wong, S.W., Leung, P.T., Djurisic, A.B. and Leung, K.M., 2010. Toxicities of nano zinc oxide to five marine organisms: influences of aggregate size and ion solubility. Anal Bioanal Chem, 396(2): 609-618.

https://doi.org/10.1007/s00216-009-3249-z 